\title{
Kumaravadivelu's Framework as a Basis for Improving English Language Teaching in Saudi Arabia: Opportunities and Challenges
}

\author{
Afnan Masaoud Ahmad ${ }^{1}$ \\ ${ }^{1}$ The Ministry of Higher Education, Saudi Arabia \\ Correspondence: Afnan Masaoud Ahmad, The Ministry of Higher Education, Saudi Arabia. E-mail: \\ diamond-dark-red@hotmail.com
}

Received: December 5, 2013 Accepted: January 22, 2014 Online Published: March 6, 2014

doi:10.5539/elt.v7n4p96 URL: http://dx.doi.org/10.5539/elt.v7n4p96

The research is financed by the Ministry of Higher Education, Saudi Arabia

\begin{abstract}
This paper discusses the issues with EFL teaching in Saudi Arabia, including the reliance on traditional teaching methodologies and banning use of first languages in classrooms. As a result, these traditional teaching practices produce less proficient learners who have limited knowledge about proper linguistic use. In order to overcome these issues and have proficient learners who can effectively use the language, however, language teachers should understand an effective change is required. Kumaravadivelu's framework (2006) is an opportunity for teachers to adopt new methods because it relies on global-level strategies, macrostrategies, that are general enough to allow teachers the opportunity to freely adjust their precise implementation in relation to individual teaching demands, along with more particular implementation tactics, microstrategies, that operationalize the macrostrategies in flexible and customizable ways according to perceived needs during the in-context process of teaching.
\end{abstract}

Keywords: Kumaravadivelu's framework, EFL teaching in Saudi Arabia, negotiated interaction, intuitive heuristics, integrating language skills, cultural awareness, innovation

\section{Introduction}

Teaching English around the world has different patterns and situations based in cultural and linguistic contexts. Contexts differ regarding the subjects of learners' needs, preferences, and aims. As an influential writer in the field of Applied Linguistics, Kumaravadivelu has offered a framework to accommodate the fact that language learners' needs and preferences tend to be unpredictable.He holds that teachers cannot be trained to use a single universal method to address these unexpected needs and preferences. Kumaravadivelu (2006) (Note 1), building on his previous work $(1992,1994,2003)$ demonstrates thatteachers should have the freedom to make their own on-going decisions regarding initially unforeseeable needsto have a successful learning process. To that end, teachers should be provided with broad guidelines which set out general strategies that are therefore applicable almost anywhere. Teachers will have a useful degree of autonomy and the broad guidance to refer back to when dealing with context-specific challenges. Kumaravedivelu's (2006, p. 201) framework relies on global-level strategies called "macrostrategies" general enough to allow teachers the opportunity to freely adjust their precise implementation in relation to individual teaching demands, along with more particular implementation tactics called microstrategies that operationalize the macrostrategies in flexible and customizable ways according to perceived needs during the in-context process of teaching.

Since Kumaravedivelu's framework is not only clearly principled, but also subtly adaptable, it has the potential for successful adoption in Saudi Arabia. This way of teaching can maintain identifiable and measurable overall goals, while realistically recognizing Saudi English as Foreign Language (EFL) teachers' and learners' characteristic beliefs and values. Such a balance will lead to the smoothest possible acceptance of instructional changes by teachers and learners alike, a key concern when planning any innovation (Rogers, 2003, pp. 15-16). For example, as Rogers predicts, if Saudi teachers realize that Kumaravadivelu's flexible macrostrategy guidelines offer the benefits of improved educational outcomes and readily accommodate specific classroom routines - microstrategies - that parallel their perspectives and concepts about teaching and encourage them to 
make their own classroom decisions, they will be more willing to adopt the overall macrostrategies without concern that doing so will inevitably lead to a demand for controversial in-class practices.

A certain degree of caution is required. As Rogers (2003, p. 1) illustrates, even advantageous and well-designed innovations may meet with resistance at the outset. Teachers should be very careful when approaching recommendations for implementing Kumaravadivelu's (2006) new framework. Widdowson (1983, pp. 162-163) argues teachers must not adopt a passive role, but they should be practical practitioners who can carefully implement and adopt new concepts regarding appropriate instruction. Thus, this essay will begin with a general introduction to Kumaravadivelu's (2006) overall macrostrategy model, followed by a survey of the literature on the EFL context in Saudi Arabia. This permits selection of a limited number of key macrostrategies most likely to embody important two qualities identified by Rogers (2003, pp. 13-15) as crucial for the smooth adoption of innovations. The objective will be to identify areas where a "relative advantage" that is very "clear-cut" and easy to see combines with a form of implementation that is "consistent with the existing values, past experiences, and needs of potential adopters". For EFL in Saudi Arabia, this means focusing on specific macrostrategies with a clear educational advantage and - when enacted through well-chosen microstrategies - will be appropriate at the introductory stage due to consistency with teachers' values, thereby allowing the easiest and most beneficial changes. Narrowing the discussion to four macrostrategies specifically underutilized in the Saudi EFL teaching system, this essay will suggest contextually-appropriate microstrategies to implement each of the macrostrategies.

\section{Kumaravadivelu's General Framework (2006)}

Kumaravadivelu's postmethod pedagogy may be considered a pedagogical solution for teachers all over the world. His framework revolutionizes the concept of teaching as it is no longer limited to one fixed instructional method. Instead, Kumaravadivelu's (2003, p. 33) framework allows teachers to move beyond method-based pedagogy to postmethod pedagogy. Although Kumaravadivelu's postmethod framework evolved between 1992 and 2006, it is valuable to examine details from iterations over the years to clearly discern features of the model relevant to this discussion. Kumaravadivelu's (2006, pp. 213-214) framework has the potential to equip teachers with knowledge, skill, attitude and autonomy necessary to develop their own location-specific postmethod pedagogies, instead of "taking the failed path of finding alternative methods".

Kumaravadivelu's broad framework of macrostrategies has inherent advantages. He (2003, p. 33) emphasizes that this framework empowers teachers as practitioners who build personal theories of practice and create location-specific activities. Acknowledging teachers' autonomy indicates how this framework trusts teachers' capacities to strike balance between institutional and academic constraints and their needs for autonomy. Teachers are not locked into a single teaching style, but are encouraged to freely practice, evaluate and analyze their teaching style to enact desired changes without violating institutional rules. Another advantage of Kumaravadivelu's framework is its compatibility with teachers' and learners' aims and needs. Kumaravadivelu (2006, pp. 34-35) claims the framework is flexible enough to be consistent with local educational and institutional goals; it capitalizes on teachers' past experience of and knowledge about teaching to access those resources and achieve their goals.This means the context-specific microstrategies derived from the overall framework of macrostrategies can be convergent with the values, ideas and needs of teachers and learners alike. The framework trusts teachers' knowledge and experiences and allows them to use them in teaching.

Instructors may be expected to recognize these elements of relative advantage and compatibility with values, not only key criteria for convincing people to successfully adopt new innovations (Rogers, 2003, pp. 15-16), but also highly consistent with Kumaravadivelu's (2006, p. 240) framework's relative advantage for teachers' autonomy and compatibility with their experience and ideas. Rogers claims meeting these criteria will help accelerate adoption of innovation because a new proposal needs to be objectively preferable to traditional practice, while people also need to vividly perceivethe advantages and compatibilities with their current needs and ideas. A successful solution for improving Saudi EFL teaching will require logical innovations that can be realistically accepted and enacted. 
These ten macrostrategies are based on Kumaravadivelu's (1994) work, presented in tabular form for brevity

\begin{tabular}{ll}
\hline The Macrostrategies & Description \\
\hline $\begin{array}{l}\text { 1) Maximizing learning } \\
\text { opportunities. }\end{array}$ & $\begin{array}{l}\text { A social activity in which both the teacher and the learners are the creators and } \\
\text { facilitators of this activity. It encourages an interactive and collaborative leaning } \\
\text { environment, where both teachers and students are partners in this activity. (p. 33) }\end{array}$
\end{tabular}
2) Facilitating negotiated Involving learners in interactional activities where they clarify, modify, and request interaction. input, which in turn influence turn taking. Learners make their own effort to continue interaction with peers and to avoid breakdowns in this interaction. (pp. 33-34)

3) Minimizing
perceptual mismatches.
Noticing any misunderstanding between their intention and learners' interpretation in order to overcome this misalignment and achieve learning. Specifically, teachers should be fully aware of different types of mismatches that may occur with learners because they can negatively affect learners' understanding. (pp. 34-36)

\begin{tabular}{ll}
\hline 4) Activating Intuitive & Creating a fruitful linguistic environment that stimulates learners' intuitive \\
Heuristics. & problem-solving insights and encourages them to understand new input implicitly. \\
& (p. 36)
\end{tabular}

\begin{tabular}{ll}
\hline $\begin{array}{l}\text { 5) Fostering Language } \\
\text { Awareness (LA). }\end{array}$ & $\begin{array}{l}\text { Promoting LA stresses learners' oriented, cyclical and holistic potential to acquire } \\
\text { understanding, general principles and operational experience, instead of relying on } \\
\text { memorization. (p. 37) }\end{array}$ \\
\hline $\begin{array}{l}\text { 6) Contextualizing } \\
\text { Linguistic Input. }\end{array}$ & $\begin{array}{l}\text { All language features cannot be comprehended in isolation, but instead, they must } \\
\text { all be integrated together in one context in order to achieve successful learning. (pp. } \\
\text { 37-38) }\end{array}$ \\
\hline $\begin{array}{l}\text { 7) Integrating language } \\
\text { skills. }\end{array}$ & $\begin{array}{l}\text { All language skills (productive and receptive) should be connected in order to } \\
\text { facilitate the most effective language learning. Learners seem to use parallel } \\
\text { integration for their skills in the classroom, which supports the claim that all } \\
\text { language skills are interrelated and cannot usefully be taught in separation from } \\
\text { others. (pp. 38-39) }\end{array}$
\end{tabular}

\begin{tabular}{ll}
\hline $\begin{array}{l}\text { 8) Promoting learner } \\
\text { autonomy. }\end{array}$ & $\begin{array}{l}\text { Each learner requires the opportunities to process and acquire the language } \\
\text { differently through multiple strategies. To increase learners' self-reliance, teachers } \\
\text { should provide them with the necessary equipment for self- direct learning, } \\
\text { strategies to stimulate their heuristic sense, and a suitable context to promote } \\
\text { implicit learning. (pp. 39-40) }\end{array}$ \\
\hline $\begin{array}{l}\text { 9) Raising cultural } \\
\text { consciousness. }\end{array}$ & $\begin{array}{l}\text { Stern (1992) claims that raising students' consciousness of the target culture } \\
\text { develops their sense of empathy and respect for the native speakers' perspectives } \\
\text { regarding certain aspects of life (p. 216). Consequently, L2 learning will be more } \\
\text { manageable and achievable if students have sociocultural awareness. (pp. 40-41) }\end{array}$ \\
\hline $\begin{array}{l}\text { 10) Ensuring social } \\
\text { relevance. }\end{array}$ & $\begin{array}{l}\text { Teachers should connect what learners learn in the classroom with their social, } \\
\text { political, educational life in order to achieve effective results. (p. 42) }\end{array}$ \\
\hline
\end{tabular}

\section{Features of EFL Teaching in Saudi Arabia}

Teaching English in Saudi Arabia began around 1925 (Al-Ahaydib, 1986, pp. 1-2) and, according to Liton (2012, p. 130), since that time the main aim of English teaching in Saudi Arabia has been to master this international language and use it to communicate with English-speaking communities. The goal has been to equip Saudi students with the necessary language to exchange knowledge and science, as well as to share Islamic culture. The Saudi teaching system has specific characteristics (e.g., teachers are often encouraged to make connections between teaching and Islam). Sywelem, Al-Harbi and Fathema (2012, p. 10) argue that each society has a distinctive learning style influenced by culture and religion. The Saudi teaching and learning style is affected by the official religion, Islam, and its goal of providing EFL learners with an international language to spread an authentically positive and peaceful outlook about the religion while confronting negative and misleading concepts about it (Ministry of Education of Saudi Arabia, n.d).

The Saudi EFL teaching context has characteristics important for understanding it: teacher-centered instruction 
and traditional language-teaching methods. Fareh's (2010) study investigated the challenges of teaching English in the Arab world, including Saudi Arabia. The findings demonstrate the issue of using teacher-centered activities as the predominant type of classroom activity across the region. Fareh explains that teachers speak most of the time, even more than students, and do not encourage learners to speak during class. Interestingly, Al-Seghayer (2007) indicates that the Saudi teaching style centers on teachers as the core of the learning process while neglecting learners, which explains the trend towards lecturing most of the time.

The second key feature is Saudi EFL teaching's—reliance on outdated methods. Al-Seghayer (2007) emphasizes that Saudi teachers follow traditional methods of language teaching: audio-lingual and grammar-translation. Such methodological choices mean that teachers will use explicit instruction, teaching discrete skills, overlooking oral fluency, and memorization of grammatical rules. Fareh $(2010$, p. 3603) argues that EFL teachers still believe the fallacy that skills are best taught in separation. Another aspect of outdated methodology observed by Liton (2012, p. 141) is banning the use of learners' first languages, which removes a resource for facilitating language learning. Al-Nofaie (2010, pp. 74-75) conducted a study to explore Saudi teachers' opinions of L1 use in class. Although the three participant teachers acknowledged the use of the L1, they attempted to avoid using Arabic in class. They explained that by not allowing the L1 in the class, learners would have more opportunities to practice the target language; however, current methodologists (Auerbach, 1993, pp. 18-19; Vanichakorn, 2009, pp. 11-12) recognize the potential of permitting limited use of the L1 in the classroom. Thus, Al-Nofaie (2010) presents evidence that Saudi teachers still follow outdated methods of teaching, specifically by banning L1 use. In view of these features of the Saudi teaching system, in Kumaravadivelu's macrostrategy framework learners will experience a particularly acute lack of opportunities for exposure to four macrostrategies: negotiated interaction, activation of heuristic exploration, integration of language skills, and cultural awareness. Thus, these four selected macrostrategoes will be the focus of this essay. Each will be considered in sequent to determine their relevance and efficacy.

Regarding negotiated interaction, Fareh (2010, p. 3602) demonstrates how speaking skillsare most neglected and in need of improvement because teachers' speak most of the time. As a result, this neglect fosters less interaction between teachers and learners; there are few sequences of questions back and forth between them. Brock (1986) and Qashoa (2013) emphasize that most EFL teachers tend not to ask referential questions or questions seeking open-ended answers containing new input (Kumaravadivelu, 2003, p. 50). Thus, teachers tend toemphasize display questions instead - further hindering chances for negotiated interaction. Al-Muaini (2006, pp. 3-6) conducted a study to investigate whether asking referential questions can increase learners' oral contribution in class. The researcher found asking referential questions increases participants' responses and contributes to classroom interaction (i.e. referential questions trigger longer answers and increase participants' willingness to participate). For heuristic learning, the Saudi learner's extremely limited opportunities to develop a heuristic sense of self-discovery learning can be traced back to teachers' speaking most of the time and their providing deductive rather than inductive explanations to learners. Fareh (2012, pp. 3603-3604) claims that Saudi EFL teachers do not facilitate learners' self-discovery because of their tendency to speak too much during the class. Also some journals, such as Al-Riyadh (2011) and Asharq Al-Awsat (2013), have published reports identifying the lack of rich linguistic settings as a major reason behind learners' failure to engage in self-discovery. Thirdly, Saudi EFL teachers' concentrate chiefly on promoting certain individual skills — specifically grammar-without integrating all skills in one teaching/learning discourse. Multiple researchers (Fareh, 2010; Liton, 2012; Khan, 2011) indicate most Saudi EFL teachers still believe in the grammar-translation method and consider grammar as the most crucial aspect of the language to master. Fareh (2010, p. 3603) argues many EFL teachers in the Arab world teach grammar independent of reading and writing. They reduce learners' communicative competence by failing to contextualize input in the sense of encouraging the synergistic development of skills together. Finally, in terms of cultural awareness, most current Saudi textbooks do not relate the language to its culture; that is, learners are exposed to the language without encountering its culture. Al-Seghayer (2013) complains that in the Saudi classroom, language is taught separately from its culture due to a call for the inclusion of local and Islamic cultural elements rather than Anglophone cues. As a consequence, learners have little or no context for the development of sociocultural awareness because they are not aware of how the language functions in its real environment. In sum, although the two major background decisions - teacher-centered teaching and outdated methods - seem motivated by a wish to take responsibility and deliver methodologically principled instruction, they give rise to very infrequent use of the four macrostrategies indicated previously and, as such, these decisions cannot be expected to succeed.

Indeed, EFL Saudi teachers seem to follow these fallacious practices - teacher-centered instruction, and outdated methodologies - on account of positive intentions, important to recognize because they have the potential 
starting points for a willingness to innovate. Al-Nofaie (2010) and Fareh (2010) claim teachers take these positions because they want to control the large number of learners in their classes and provide them with as much useful information as possible. Ellis (2008, pp. 797-798) supports the notion that teachers tend to lecture, instead of interacting with learners, to have control over the discourse and to emphasize meaning and grammatical accuracy over communication. Al-Hazmi (2003, pp. 342-344) believes some EFL teachers cannot meet the increasing demand for more communicative activities in the EFL classroom because they lack sufficient linguistic knowledge, appropriate teaching methods, and language proficiency. Li (1998, p. 687) claims: "The fear of losing face because of not being able to answer students' questions all the time discouraged teachers from using CLT". Finally, in terms of banning the L1, Saudi EFL teachers do so to realize their perceivedresponsibility to force learners to practice language skills (Al-Nofaie, 2010, p. 75). Viewed in this light, these choices can all be understood as positively-motivated decisions.

Nevertheless, with increasing awareness regarding the importance of the English language and how to facilitate its acquisition, EFL teaching practices in Saudi Arabia are beginning to change. Al-Seghayer (2012) and Liton (2012) indicate EFL teachers are now interested in the English language because it serves multiple functions with an eminent position within the Saudi society. Liton (2012, pp. 142-146) conducted an experiment to investigate teachers' and learners' perceptions about English. The participants were 94 Saudi teachers and 380 Saudi students asked to answer a questionnaire. The findings demonstrated both teachers and learners recognized the need for improvement in the EFL teaching system. An overwhelming portion of the participants indicated an urgent need for a strong and friendly relationship between learners and teachers, instead of the traditional distance between teachers and students (Liton, 2012, p. 143). Further, they agreed on the possible value of using their first language in the classroom for effective involvement by learners (Liton, 2012, p. 141). Generally, they acknowledged that understanding the drawbacks in EFL teaching in Saudi Arabia as a starting point for initiating change and promoting adoption of new strategies to improve teaching practices. In fact, teachers' and learners' perceptions about the growing need for development in teaching practices can be expected to accelerate the adoption of new innovations - such as Kumaravadivelu's macrostrategy framework-because of a willingness to look for clear improvements in the EFL teaching system. Fortunately, Kumaravadivelu's framework is deliberately designed for teachers in different settings to allow them to adapt to their particular context.This essay will demonstrate the ways in which adaptation can be achieved.

\section{Examples of Macrostrategies to Promote Improved EFL Outcomes in Saudi Arabia}

In what follows, I will present examples of macrostrategies that can be used to improve EFL teaching and learning in the context of Saudi Arabia.

\subsection{Facilitate Negotiated Interaction}

Kumaravadivelu (2006, p. 202) defines negotiated interaction not just as students' reacting and responding to teachers' questions, but the full flexibility and involvement of learners in the learning process to initiate interaction and modify their responses to avoid breakdown - there should be purposeful interaction among learners and between learners and their teacher. Both Kumaravadivelu (2003, p. 102) and Ellis (2008, pp. 205, 252) confirm that during this interaction, rich opportunities are available for learners to expand their comprehension of input and acquire new input, leading to increased L2 acquisition. They even suggest that interaction can foster language attainment because it supplies language learners with opportunities to receive new input, to produce output, and to modify their production after feedback from their teachers.

A number of studies in applied linguistics have explored the effect of negotiated interaction on acquiring various language features. Fuente (2002, pp. 90-93) examined the long-term impact of negotiation on comprehension and vocabulary acquisition: namely, receptive and productive vocabulary. To explore the effect of negotiation, there were three groups of second language learners: a group with non-negotiated premodified input (NNPI) - required to listen to the instruction provided without any interaction - and two other groups, one with negotiated input without output (NIWO), and the other with negotiated input plus output (NIPO). The latter groups were encouraged to interact with their instructors, by modifying their output and producing the target feature. Even though the study has some limitations, such as examining the acquisition of only a single lexical category (concrete nouns), the general findings support the effectiveness of negotiated interaction on comprehension and vocabulary acquisition. In particular, Fuente indicated that the NIWO and NIPO groups surpassed the other NNPI group in acquiring the target vocabulary after only three weeks. This study is empirical evidence that negotiation and interaction facilitate comprehension and L2 vocabulary attainment. Likewise, Rezvani (2011, pp. 679-680) set out to determine whether negotiation, specifically input enhancement or output requirement, has a beneficial influence on acquiring grammatical collocations. He compared one control group 
(CG) with two experimental groups (EG 1 \& EG 2). The findings indicated that involving the participants in negotiated interaction - input enhancement and output requirement—promoted their acquisition of grammatical collocations. Regardless of the drawbacks of the study - it examined collocations only, not other grammatical rules - we may infer that negotiation can positively impact the attainment of certain grammatical features. These studiesstrongly support Long's (1996, pp. 451-452) claim that "negotiation for meaning... facilitates acquisition because it connects input, internal learner capabilities, particularly selective attention, and output in productive ways". All these findings are parallel to Fotos and Ellis's (1991, p. 193) claim that learners can acquire any linguistic featurewhen they are involved in interactional situations that require them to achieve communicative purposes.

Such studies reveal the influence of negotiated interaction on language acquisition. Saudi Arabian teachers are likely ready to implement more interaction within the classroom. Kumaravadivelu's (2003, p. 102) macrostrategy clearly identifies activities that can engage learners in negotiated interaction by outlining three types of interactional activities. The first is textual activities using different linguistic and metalinguistic features to enable learners to understand new input. The second is interpersonal activity by using sociolinguistic features of the language to promote communication and interaction. In this instance, sociolinguistic features play an effective role in maintaining communication between learners and their interlocutors and prevent breakdowns. Ellis (2008, pp. 274-275) holds that acquisition occurs when interaction involves social and cultural factors; thus, L2 acquisition is not individually-based, but rather a dialogically-based process (Ellis, 2008, p. 526). The third type is ideational activities that use learners' personal experience, ideas and emotions to express their perspectives about events around them; such activities involve affective awareness. According to Kumaravadivelu (2003, pp. 114-115), these three types of activities can help teachers achieve their responsibility to improve learners' language by enabling them to participate in shaping and developing their language acquisition. He even suggests that a combination of these three types will provide teachers with rich opportunities to design a suitable environment for learners to expand their linguistic resources, practice their interactional ability, and exchange personal experiences.

Another strategy to implement negotiated interaction is by asking certain types of questions. Kumaravadivelu (2003, p. 49) claims that asking process questions, which seek learners' opinion about contemporary topics, and metaprocess questions, which require learners to define their reasoning and produce their remembered answers, can be expected to facilitate negotiated interaction. He categorizes these types of questions as referential questions. For example, Al-Muaini (2006), Brock (1986) and Qashoa (2013) agree that exposing learners to more referential questions will encourage and motivate them to participate and exchange input through interaction. These researchers hold that these types of question could encourage learners to produce longer and more grammatically complicated responses. Asking referential question can generate more opportunities for negotiated interaction as Kumaravadivelu (2003, p. 49) has proposed.

\subsubsection{Examples of Microstrategies to Facilitate Negotiated Interaction in Saudi EFL Classes}

Many microstrategies enact the macrostrategy of negotiated interaction in practical activities that initiate classroom interaction. EFL teachers need to be fully aware that these microstrategies should promote three types of activities - textual, interpersonal and ideational- to expand students' linguistic resources, practice their interactional skills, and exchange personal experiences. Further, EFL teachers should know these activities could be adjusted for consistency with specific learners' preference. In other words, teachers may actually increase their professional experience of autonomy.

Negotiated interaction microstrategy 1: Vacations and destinations. In this activity, Saudi EFL teachers can promote negotiated interaction while retaining responsibility for controlling the classroom and creating a suitable environment for learning. For example, when working with advanced learners, EFL teachers can require students to search the Internet at home about the topic to prepare a short talk about their favorite statutory holidays in Saudi Arabia according to the Islamic calendar, or interesting destinations for vacations, whether in their hometown or internationally. During that out-of-class task, teachers can help learners to search for information about the holidays, the climate in their chosen destination, the clothing they should have there, and, also, ideally, ask them to provide photos and illustrative Web pages about the destination. In the classroom, teachers should require learners to listen to one another carefully, take notes, and, at the end, reflect on each of their interlocutors' talks. Moreover, teachers can initiate discussion by talking about their own favorite holiday and destination to familiarize learners with the pattern of the activity. At the next stage, each learner can start by presenting a talk for a short time and then letting peers discuss it, offer comments, ask referential questions for opinions and clarification, and reflect on what they have heard. After this discussion, each learner can modify and revise his or her talk. At the end of each talk, teachers can briefly evaluate the presentation by concentrating 
on the positive points, offering suggestions for improvement, and inviting class members to make suggestions.

Saudi EFL teachers will be able to relate this activity to learners' culture and religion to realize the national policy regarding such learning outcomes. For example, teachers can ask learners what type of clothing is appropriate for the destination. Additionally, teachers can ask learners whether they know other non-statutory holidays in Saudi Arabia. By doing so, teachers will be able to provide additional opportunities for learners to interact and receive new input about content that may not be known to all of students. If learners are given the chance to express their interests and preferences, they will be enthusiastic about interacting and communicating with their teachers and classmates (Kumaravadivelu, 2003, p. 125).

Overall, an activity of this type will be culturally appropriate, and also allow the teacher to remain in the position of classroom manager, while also invoking all three forms of negotiated interaction: textual, interpersonal, and ideational activities. Textual activity may be supported by referring to the photos and Web pages that learners bring and asking learners to describe them; interpersonal involvement may be elicited by requiring learners to read their short talk aloud, while their interlocutor take notes and ask for elaboration; and an effective ideational activity could be provided by encouraging other peers to express opinions regarding different destinations and whether they are appropriate according to Islamic culture.

In sum, negotiated interaction is an essential macrostrategy within Kumaravadivelu's framework with strong relevance for improving EFL instruction in Saudi Arabia. In a classroom where negotiated interaction is predominant, teachers and learners are fully aware of the collaborative effort required to create a rich environment for textual, interpersonal, ideational interactional activities, and referential questions. Enacting this macrostrategy through practical microstrategies as presented above will appeal to Saudi EFL teachers. First, it connects the potential for improved learning outcomes with Saudi EFL teachers' willingness to change their traditional teaching practices (Liton, 2012, p. 142). Second, the relative advantage of such techniques for teacher autonomy and compatibility with teachers' and learners' beliefs should facilitate their adoption. On this basis, increased negotiated interaction in EFL teaching and learning is proposed as an innovation that likely succeeds in Saudi Arabia.

\subsection{Activate Intuitive Heuristics}

Intuitive heuristics involves a method of teaching that enables L2 learners to recognize new linguistic input without explicit instruction (Kumaravadivelu, 2003, p. 176). In a similar vein, Ellis (2009, p. 3) calls heuristic exploration implicit learning, which occurs without requiring explicit attention to the learning process, although its progress is clear in learners' responses to teachers' questions. Adair-Hauck, Donato and Cumo-Johanssen (2005, p. 149) explain how teachers are seen as providers of linguistic input, instead of explainers in heuristic exploration. Kumaravadivelu (2003, pp. 176, 185) and Ellis (2009, p. 17) agree that teachers' responsibilities during implicit teaching are to supply learners with sufficient material to trigger their discovery or heuristic exploration, and create the appropriate linguistic environment to contextualize the target feature.

Several studies have investigated the effectiveness of inductive or implicit instruction on learners' performance (Herron \& Tomasello, 1992; Vogel, Herron, Cole, \& York, 2011). These researchers examined the impact on learners' perception and performance of teaching certain French grammatical features inductively and deductively. The participants in Herron and Tomasello's (1992) study were 26 beginner students, while Vogel et al.'s (2011) study focused on 40 intermediate learners. Although both studies have limitations - for example, conducting the studies on only French learners and thus limiting generalizability to other subsequent-language learning contexts - the results yielded positive indications for inductive teaching. Vogel et al. (2011) demonstrated that participants' performance in short-term learning was statistically significantly higher after inductive teaching than deductive (p. 363). These findings are consistent with Herron and Tomasello's (1992) study, which found a positive correlation between acquiring target features and teaching them inductively. Although $80 \%$ of the participants in Vogel et al. (2011, p. 365) showed a clear preference for deductive teaching, the results of the immediate test after treatment illustrated that participants performed better on the basis of inductive rather than deductive teaching. The results of both studies encouraged the researchers to argue that teaching inductively can result in more active learning, when learners interact with teachers to formulate a hypothesis about the target language structure and then receive teacher feedback. Herron and Tomasello (1992, p. 716) further argue that an inductive approach seems essential for constructing a clear sense of the target language. They argue, therefore, for engaging teachers' willingness to adopt an inductive approach because of its beneficial impact on learners' participation, interaction, and collaboration.

Having described the essence of active, inductive teaching, it is necessary to consider appropriate strategies to activate heuristic learning. Kumaravadivelu (2003, p. 188) suggests that EFL teachers can stimulate learners' 
heuristics by providing adequate linguistic input to encourage discovery of a given target feature. One way to do so is through contextualizing the input, as Herron and Tomasello (1992) and Vogel et al. (2011) did.These researchers followed the PACE model developed by Adair-Hauck et al. (2005, p. 153) to highlight a vital concept where this model does not abandon any explicit explanation, but helps teachers to understand "how, when, and where to focus on form [i.e. explicit instruction] in a lesson that will ultimately clarify this important design feature of foreign language instruction”. They classify this model in four main stages:

1) The presentation phase of the input through using stories and authentic materials.

2) The attention phases in which teachers ask questions about different patterns within the story without explicit elaboration.

3) The co-construction phase when teachers and learners collaborate together to construct the input without direct explanation.

4) The extension phase is done through engaging learners in certain types of activities - authentic writing project and paired interviews - that require learners to use the target input (pp. 154-157).

In Herron's and Tomasello's (1992, p. 712) experiment, oral practice was used to direct participants' attention to the feature, whereas Vogel et al. (2011, p. 359) adopted a contextualized question-answer activity with visual support. Kumaravadivelu (2003, p. 188) argues that another technique to facilitate inductive teaching is through meaningfully negotiated interaction that guides learners' attention to the target feature. Fotos and Ellis (1999, pp. 622-623) argue that teaching grammar through interaction instead of formal grammar lessons may foster L2 attainment because it encourages implicit, discovery-oriented learning. Furthermore, all such claims regarding the advantages of teaching inductively are similar to Thornbury's (2011, pp. 54-55) argument that inductive teaching can promote learner collaboration and extra language practice through interaction with interlocutors, and also ensure greater learner involvement in the learning process. By doing so, learners will be more attentive and motivated to participate in the classroom.

\subsubsection{Examples of Microstrategies to Activate Intuitive Heuristics in Saudi EFL Classes}

Since implicit teaching or the heuristic learning approach is valuable to learners and teachers, EFL teachers can design various activities to enact this theoretical approach in practical classroom activities. In particular, the following microstrategies should be appealing to EFL Saudi teachers because they are compatible with their beliefs and their learners' preferences.

Activate intuitive heuristics microstrategy 1: Cloze test (Ramadan). This task will focus on promoting learners' vocabulary acquisition and understanding of Ramadan through a fill-in-the-blanks activity. Richards and Schmidt (2010, p. 85) define the cloze activity as a technique in which instructors delete certain words from a passage to have learners guess the appropriate words. The teacher should either write or select a short passage with specific new English vocabulary associated with the topic of Ramadan (e.g., charity, fasting, worship, self-discipline, circumambulation, sunrise, sunset, appreciation, and poverty) and delete them from the passage. The teacher should be aware that although learners know the underlying concepts, this English vocabulary will be unfamiliar to them so it is better to supply them with a table of the missing words. Using both unfamiliar and familiar vocabulary terms will help learners to manage the challenge of the task. In class, the teacher must provide clear instructions on how to do the activity and allow questions for clarification, if necessary. Learners should complete the task individually using the provided table of vocabulary after reading the passage. Next, the teacher can facilitate interaction through dividing learners into pairs to compare their answers. During this stage, learners should negotiate their choices of words and provide their partners with simple definitions for the words. The teacher can increase interaction through requiring partners to determine one correct word for each blank. Then, each pair should report their answers to their classmates and explain their choice if there is difference between the groups. At this stage, if learners cannot infer any of the new words, the teacher should help learners implicitly notice clues to the meaning because the aim is to activate heuristic exploration. To assure lasting acquisition of the target feature, at the end of the activity the teacher can ask groups to compose their own sentences containing the vocabulary.

Like other activities suggested, this task seems culturally relevant and consistently compatible to EFL Saudi teaching practices. The activity will still support teachers' need to lead the class and provide help for learners as they achieve learning, while concurrently creating a more active learning environment through implicit teaching. In fact, as Rogers (2003, pp. 15-16) argues, compatibility with teachers' and learners' ideas and culture is a predictor for successful adoption of this type of activity, especially when teachers and learners are keen for new teaching practices. Therefore, the activity may well be perceived as offering multiple benefits through which the 
teacher can develop learners' interactional, listening, writing, and cognitive skills.

To conclude, Kumaravadivelu's $(1994,2003)$ framework argues foractivating intuitive heuristics as an important goal. Adopting such a macrostrategy or framework within EFL Saudi instructors' repertoire of teaching practices is suitable due to advantages and compatibility with EFL Saudi teachers' and learners' preferences and needs, as well as Saudi instructors' willingness to consider new teaching styles documented above. EFL teachers should be encouraged to recognize that promoting self-discovery does not limit their constructive ability to guide classroom discourse instead it will enhance classroom management through involving learners in the learning process and guide them to discover and improve their own intellectual knowledge.

\subsection{Integrate Language Skills}

Integrating language skills is another crucial technique for effective L2 learning. This technique refers to incorporating all language skills, productive and receptive, in one discourse. Richards and Schmidt (2010, pp. $288,635)$ define this approach as connecting reading, writing, speaking, and listening together in one activity that can be taught through a holistic method. Integrating language skills can be described as a whole-language approach or a multi-skill syllabus because these terms are interchangeable. Several scholars have affirmed the need for the integration of skills (Harmer, 2007; Kumaravadivelu, 2003; Selinker \& Tomlin, 1986) because in real life people utilize all their language skills to achieve communication and it is unnatural to separate skills during classroom interaction. Similarly, Selinker and Tomlin (1986, pp. 227-228) justify integrating language skills because there is no reason behind separating them. They argue that language teaching methodology should move from teaching segmented skills towards integrated skills.

Oxford (2001, p. 5) has also advocated the vital advantages of an integrated-skills approach (ISA) for L2 development. She suggests integration of language skills will expose learners to actual language use and encourage interaction. Then, the ISA has the potential to reshape learners' perception of the language as both interaction and communication. This approach also enables teachers to see their learners' skills develop realistically. Last, the ISA can influence learners' motivation to learn the language. A study by Su (2007, pp. 32-35) affirms the effectiveness of the ISA on learners' perceptions about English and their motivation. Specifically, Su conducted a study to explore learners' performance during the ISA and their opinion of the approach. During the experiment, Su found that most participants, 64 Taiwanese college students, perceived the need for authentic communication through integrating all skills and recommended using the ISA in class. They related their preference for ISA to an active environment with insightful interaction, which consequently motivates practice of their skills. The researcher concluded that learners are motivated to learn and improve their language with the ISA, leading to enhanced L2 development.

Since it is unreasonable to teach each skill separately (Selinker \& Tomlin, 1986; Harmer, 2007) and, since the ISA is advantageous for L2 development, EFL teachers should combine language skills to achieve effective L2 learning. Harmer (2007, p. 267) and Kumaravadivelu (2003, p. 229) propose several classroom activities with potential to integrate all language skills. Some are interactional activities - such as problem-solving-and integrated tasks. Consistent with this, Ellis (2003, pp. 69, 78-80) argues that interaction influences the course of language attainment because these activities, such as problem-solving, are intended to use all language skills through negotiation. That is, learners are engaged in a constant cycle of "pouring back and forth" between listening, writing and speaking. Stern (1992, p. 198) also identified a similar cycle during problem-solving activities where learners are required to examine a problem, discuss it, and write possible suggestions. There seems to be extensive corroboration that interactional activities, including problem-solving, positively contribute to language acquisition as Kumaravadivelu proposes. Harmer (2007, p. 267) argues that integrated tasks mostly operate through using multiple skills. For instance, in an integrated speaking activity, learners are required to speak, listen to each other, write notes, and read their own notes. Consequently, such tasks tend to be impossible to successfully achieve using only one skill.

\subsubsection{Examples of Microstrategies for Integrating Language Skills in Saudi EFL Classes}

The following microstrategies can integrate multiple language skills—speaking, listening, writing, reading, and grammar - to address current deficiencies; however, these microstrategies can still be perceived as being parallel to EFL Saudi teachers' and learners' needs and beliefs.They will also be attractive enough for adoption because of the opportunities these activities provide for achieving effective learning that leads to L2 development.

Integrating language skills microstrategy 2: Integrated task (pictures from the past with past simple and past progressive). In this activity, the EFL teacher and the learners will have an active and effective learning environment due to learners' full investment in the learning process. This activity may enable the EFL teacher to stimulate use of all language skills, and simultaneously review learners' understanding of the past tense. First, 
the teacher asks each learner to bring three or four pictures about various events from the past and prepare a short speech about each picture. In class, learners receive instruction about how to do the task. For example, each learner will speak about the pictures for about four to five minutes in front of the class, using the past tense, while their classmates listen and take notes. The teacher can initiate the activity by giving his or her own talk about three pictures from the past, using the past tense, to familiarize learners with the pattern. After each learner's speech, the teacher should allow class members a few minutes to read their notes and ask questions of the speaker. This step will encompass interaction and negotiation as listeners are expected to ask the speaker for clarification, or they may check for accurate grammar structures because the presentation will have been about the past. Finally, the teacher should ask learners whether they perceive the advantages of and understand the aim of the task.

In fact, an activity like this has the potential for consistency with Saudi EFL teachers' and learners' needs and beliefs. Initially, the teacher has control over the discourse and the learners because of their role in helping move the activity from stage to stage and leading learners in perceiving the significance of the activity. Further, it is compatible with learners' needs because it focuses on promoting all language skills, which contribute to L2 acquisition as Ellis (2003, p. 69) affirms. In addition, the activity facilitates all language skills: learners speak, listen, write and read their notes to follow each presentation and ask questions. Learners are fully involved in active and effective learning. Thus, EFL teachers should be willing to adopt this activity, not only because it advances their goals, but also because it creates an effective learning environment.

Overall, Kumaravadivelu's framework argues for integrating language skills as an essential macrostrategy. As indicated, natural communication cannot occur without combining: speaking, listening, writing, and reading. Kumaravadivelu provides EFL teachers with an opportunity to connect all language skills to engage L2 learners in the meaningful and active use of language within his macrostrategy framework. This opportunity should strengthen EFL teachers' management by guiding the learning process to achieve its objectives and by encouraging learners to engage in meaningful interaction.

\subsection{Raise Cultural Consciousness}

The last vital macrostrategy for any EFL teaching context is raising learners' cultural consciousness. Kumaravadivelu's framework advocates connecting L2 language teaching to the target language's culture. Stern (1992, p. 207) demonstrates that after World War II various anthropological studies emphasized the concept of connecting the life-style of a community to its language during teaching. Thus, Kumaravadivelu (2003, p. 267) indicates that, in any ESL or EFL teaching context, teachers and learners alike should necessarily highlight behaviors, values, and beliefs fundamental for understanding the life of the native speakers of the target language. According to Stern (1992, p. 212) and Kumaravadivelu (2003, p. 268), EFL teachers should do so to help learners gain cross-cultural understanding and communication skills (i.e., learners will create an image about how to use the language in a culturally appropriate way consistent with native speakers' use). Both Kumaravadivelu (2003) and Stern (1992) argue for joining language teaching to the target culture because they are intertwined.

Some scholarly studies (Bateman, 2001; Su, 2008) have investigated the positive impact of ethnographic interviews on EFL learners' attitude towards the language. Initially, ethnographic interviews referred to a teaching strategy aimed to develop L2 learners' cultural understanding of the target language through interviewing and interacting with native speakers (Richards \& Schmi6dt, 2010, p. 204). Although Bateman's (2001) and Su's (2008) studies have some constraints - the small sample size and limited time to conduct the studies - both experiments' results are consistent with Kumaravadivelu's and Stern's claims regarding the positive influence of connecting language to culture. Specifically, Bateman (2002, pp. 322-326) and Su (2008, pp. 384-390) concluded that interviews with native speakers of the two languages, Spanish and English, encouraged participants to build positive attitude towards the languages and cultures. The researchers even affirmed that because of having interviewed native speakers, the participants developed critical intercultural understanding of their native culture and the target culture. They began to confront various misconceptions about the two languages and improved their knowledge of both. These findings should be a positive indication that culture teaching - through ethnographic interviews - can accelerate learners' sociocultural understanding and communication skills, which contribute to L2 learning and acquisition. The results are parallel to what Stern (1992, p. 218) argues:

Parallel to the teaching of language, the teaching of culture can be regarded as leading to a generalized sociocultural competence to certain sociocultural skills, or to specific socioculturally appropriate behaviour ... 
culture teaching ... should lead to cultural proficiency; that is, the learner is acquiring the skills to conduct himself in socioculturally appropriate ways.

Since acquiring the linguistic features of a language without understanding their culturally appropriate use is impractical (Doye, 1996, p. 105; Risager, 2007, p. 11), language teachers should continuously provide a rich sociocultural environment to trigger L2 learners' cross-cultural understanding and language competence. Ethnographic interviews with native speakers can do this, as can authentic materials and activities. Although the former strategy may appear difficult in an EFL context, it would be possible to arrange a visit by a native speaker to an EFL class, especially due to migration, which facilitates finding native speakers in urban communities as Stern (1992, p. 231) points out. Indeed, Bateman (2002, p. 320) argues that exposing L2 learners to face-to-face interaction with native speakers can positively foster learners' intercultural perceptions. Stern (1992) maintains a parallel feature when he notes the best technique to bring an L2 to life is through interacting with individuals from the target culture. By doing so, learners acquire a better understanding of native speakers' opinions regarding various cultural events. A second technique for reaching this goal is through creating and using authentic materials. Kumaravadivelu (2003, p. 272) and Stern (1992, p. 224) both hold that using authentic materials - such as newspapers, restaurant menus, video clips and the Internet - can help teachers create culturally rich situations and increase learners' perceptions about the target language and culture. Additionally, Crossley, Louwerse, McCarthy, and McNamara (2007, pp. 17-18) affirm that authentic materials can efficiently present natural, meaningful, and comprehensible linguistic examples abundant with cultural implications. In general, EFL teachers need to create an effective connection between the language and its culture by interviewing native speakers or using authentic tasks that expose learners to the natural use of the language.

\subsubsection{Examples of Microstrategies for Raising Cultural Consciousness in Saudi EFL Classes}

There are several classroom activities to effectively and practically accomplish this macrostrategy in the classroom. EFL teachers need to ensure that any classroom task promotes learners' cross-cultural understanding and communication because this contributes to language learning. By the same token, EFL teachers should be fully aware these activities will connect the learners' own culture and the target culture to deepen their critical cultural consciousness (Kumaravadivelu, 2003, pp. 271, 275). Further, it is worth repeating that these activities can be adjusted by EFL teachers to suit their learners' preferences. This is a place where teachers' autonomous creativity can come into play, by customizing these tasks.

Raise cultural consciousness microstrategy 1: Ethnographic interview. Human migration has eased the task of conducting ethnographic interviews in the EFL classroom. This activity should become a familiar learning tool to students and teachers alike. In the pre-task stage, EFL teachers should take steps to prepare learners for the activity (interview with a native speaker). Teachers should divide the entire class into small groups and assign each group one specific cultural topic - such as women's role in the labor force, marriage at an early age (child marriage), studying in foreign countries, living within a nuclear or an extended family, or traditional greetings. Teachers should then require the learners within each group to agree on at least one question to ask the interviewee. Teachers should exemplify the best types of questions for learners to design (i.e., referential or descriptive questions). For example:

\section{Could you describe what happens in a typical marriage in Canada?}

What are some jobs that Canadian women can do? Is it similar to what Saudi women do?

What do you think about living within a nuclear family or an extended family?

How do people greet each other in Canada? Is there a difference between the typical Canadian and Saudi greeting? How?

(Adapted from Spradley, 1979, pp. 86-90)

If applicable, teachers can ask learners to use the Internet to find examples of cultural questions. During the task, teachers should allow sufficient time for each group to ask their questions of the interviewee. During the interview, learners should consistently take notes, listen carefully, and interact with the interviewee. After conducting the interview, teachers should direct each group to collaboratively write a short descriptive essay about the interviewee's responses - by discussing the difference between the interviewee's opinions and their own about the topics. In the next class, each group should present the essay and state their opinions about the topic. Finally, teachers can assure achievement of the main goal of the activity —increasing learners' cross-cultural understanding and communication - by asking what learners think about the activity and whether they perceive advantagesin interviewing a native speaker.

On one hand, the activity would enhance the teachers' position by allowing them to maintain overall management 
of the discourse as they introduce the activity, prepare the learners, arrange the groups, and plan for adequate time to conduct the interview. This management responsibility would underline the teachers' role as effective players in the learning process. On the other, it would engage learners in more active learning through interacting with native speakers and bringing language to life (Crossley et al., 2007, pp. 17-18; Stern, 1992, p. 230). It would also reinforce their intercultural knowledge andcritical cross-cultural perceptions through an opportunity to reevaluate their cultural misconceptions regarding native English speakers. This activity promotes natural language use and intercultural understanding and leads to cultural proficiency (Stern, 1992, p. 218). We can anticipate that EFL teachers will be willing to adopt this activity due to its flexibility in allowing control over the discourse, and due to its positive impact on raising learners' cultural awareness and language learning.

In sum, teaching the target language in light of its culture tends to be a fundamental element to ensure effective acquisition, which can contribute to improving EFL instruction in Saudi Arabia. In a classroom where EFL teachers always connect the target language to the target culture, teachers and learners alike must not forget that this process also involves them as informants regarding their culture. They should cooperate to create an optimal environment to build critical cultural awareness of the two cultures. Kumaravadivelu's framework advocates for such critical awareness and urges EFL teachers to help learners to evaluate their culture and the target culture alike. Achieving such awareness can be possible through conducting ethnographic interviews and using authentic materials. In fact, finding ways to enact such a macrostrategy should be tempting to Saudi teachers in light of a willingness to improve their instructional outcomes, and also because of the strategy's compatibility with their traditional culture, values, and preferences.

\section{Limitations and Conclusion}

EFL teaching all over the world has distinctive instructional traditions and preferences that differ from one context to another. Kumaravadivelu's astute recognition of the unforeseen needs and preferences of EFL teachers and learners pinpoints how and why EFL teachers cannot be expected to adopt a universal method of teaching that, in its inflexibility, fails to recognize unpredictable local requirements. Therefore, he proposes a global-level framework within which EFL teachers can efficiently and freely make adaptations to assert their autonomy, responsibility, and knowledge through context-appropriate classroom microstrategies. This framework seems not only appealing enough to be adopted - because of its acknowledgment of teachers' and learners' beliefs and values - but also effective enough for executing the general goal of EFL instruction in Saudi Arabia. Thus, there is a strong likelihood that innovations made on the basis of the framework will be accepted smoothly and willingly. In this sense, Saudi EFL teachers should recognize the potential returns of EFL instruction through the application of such a framework, especially because it takes account of their autonomy and knowledge in making classroom decisions based on their learners' needs.

Kumaravadivelu's framework revolutionizes traditional methods of teaching by releasing teachers from standardized methods' restrictions and enabling use of their knowledge and creativity in the classroom to generate context-specific classroom microstrategies based on broad macrostrategies. By the same token, the framework advocates consistency with local educational and institutional objectives for teaching; even though classroom activities are always derived from the same general macrostrategies, those activities - microstrategies - will be consistent with both educational objectives and teachers' and learners' needs. These fundamental advantages should be facilitative factors for adopting this framework to improve ELT in Saudi Arabia. These two advantages are key elements in what Rogers (2003) determines as facilitators for the adoption process of any new innovation - a relative advantage in terms of teachers' and learners' goals, and consistency with their needs and preferences.

Still, Rogers (2003, pp. 20-21,177) frequently demonstrates a critical limitation that may arise: any innovation may be resisted in the early stages due to uncertainty about the new proposal and its outcomes. In that respect, although Kumaravadivelu's framework may meet with an initial lack of enthusiasm, several scholars have confirmed that EFL teachers in Saudi Arabia are willing to adopt new instructional techniques, especially after having perceived the unsatisfactory nature of current results methods for EFL teaching. This willingness can be taken as openness to Kumaravadivelu's proposed framework. In this connection, Widdowson (1978, pp. 162-163) places responsibility for effective adoption of new innovations on teachers because they are not encouraged to see themselves as consumers of other people's thoughts and ideas, but rather as independent practitioners who can and should examine new methodologies for classroom utility and who can critically explore new approaches and strategies. Widdowson independently echoes Kumaravadivelu's confidence that language teachers will greet an increase in decision-making freedom positively.

Consequently, based on consideration of key issues for advancing ELT success in Saudi Arabia, four 
macrostrategies - negotiated interaction, intuitive heuristics, integrating language skills, and cultural consciousness - emerged as particularly underutilized in the Saudi EFL context. Accordingly, this project has identified several improvements for better EFL instruction in Saudi Arabia that offer demonstrable advantages and can be accepted on account of their compatibility with local needs and goals. As Rogers (2003) clearly indicates the adoption of innovations depends on their potential benefits and supporting aspects like their suitability to values and expectations. Consequently, adoption can be a slow process, and may fail. These are sobering facts. Nevertheless, this project has attempted to cast light on how Kumaravadivelu's suggested framework can move from being a good idea to a practical reality in the specific context of EFL in Saudi Arabia.

\section{Acknowledgements}

I would like to thank Allah, first of all, then my parents, my siblings, my supervisor, Dr. Sivell, my husband, Rashad, and my son, Yosef, for inspiring me to accomplish this project.

\section{References}

Adair-Hauck, B., Donato, R., \& Cumo-Johanssen, P. (2000). Using a story-based approach to teach grammar. In J. L. Shrum, \& E. W. Glisan (Eds.), Teacher's handbook: Contextualizing language instruction (2nd ed., pp. 146-163). Boston, MA: Heinle \& Heinle.

Al-Ahaydib, M. E. A. (1986). Teaching English as a foreign language in the intermediate and secondary schools of Saudi Arabia: A diagnostic study (Doctoral dissertation). Retrieved from http://search.proquest.com/docview/58165897?accountid=9744

Al-Hazmi, S. (2003). EFL teacher preparation programs in Saudi Arabia: Trends and challenges. TESOL Quarterly, 37(2), $341-344 . \quad$ Retrieved from http://onlinelibrary.wiley.com/store/10.2307/3588509/asset/3588509.pdf?v=1\&t=hkcoa521\&s=260c5e7f5ad 1c2359d071b7fb1968ef36315ac01

Al-Muaini, H. A. (2006). The effect of referential questions on learners' oral contributions. In S. Borg (Eds.), Classroom Research in English Language Teaching in Oman (pp. n.d.). Muscat: Ministry of Education, Sultanate of Oman.

Al-Nofaie, H. (2010). The attitudes of teachers and students towards using Arabic in EFL classrooms in Saudi public schools-a case study. Novitas-Royal (Research on youth and language), 4(1), 64-95. Retrieved from http://www.novitasroyal.org/Vol_4_1/al-nofaie.pdf

Al-Seghayer, K. (2007, March 3). Impediments teaching English in Saudi Arabia. Al-Jazirah. Retrieved from http://www.al-jazirah.com/2007/20070303/ar2.htm

Al-Seghayer, F. (2012, May 6). The psychological, administrative and systemic obstacles: Tri-driving the deterioration of English in Saudi Arabia. Asharq Al-Awsat. Retrieved from http://aawsat.com/details.asp?section=55\&article=675987\&issueno=12213\#.Ue7BPmTTW-X

Al-Seghayer, K. (2013, January 29). Teach us English but without its cultural values. Saudi Gazette. Retrieved from http://www.saudigazette.com.sa/index.cfm?method=home.regcon\&contentid=20130129151084

Al-Zahrani, R. (2011). Teaching of English in schools "successful outcome". Al-Riyadh Journal. Retrieved from http://www.alriyadh.com/iphone/article/676444

Auerbach, E, R. (1993). Reexamining English only in the ESL classroom. TESOL Quarterly, 27(1), 9-32. Retrieved from http://search.proquest.com/docview/58241808?accountid=9744

Bandar, A. (2013). Experts talk about obstacles to mastering English in Saudi Arabia. Asharq Al-Awsat. Retrieved from http://www.aawsat.com/details.asp?section=55\&article=723057\&issueno=12543\#.Ue7D4GTTW-X

Bateman, B. E. (2002). Promoting openness toward culture learning: Ethnographic interviews for students of Spanish. The Modern Language Journal, 86(3), 318-331. Retrieved from $\mathrm{http} / / /$ search.proquest.com/docview/85564973?accountid $=9744$

Brock, C. A. (1986). The effects of referential questions on ESL classroom discourse. TESOL Quarterly, 20(1), 47-59. Retrieved from http://search.proquest.com/docview/85473222?accountid=9744

Crossley, S. A., Louwerse, M. M., McCarthy, P. M., \& McNamara, D. S. (2007). A linguistic analysis of simplified and authentic texts. Modern Language Journal, 91(1), 15-30. Retrieved from http://dx.doi.org/10.1111/j.1540-4781.2007.00507.x 
Doye, P. (1996). Foreign language teaching and education for intercultural and international understanding. Evaluation \& Research in Education, 10(2), 104-112. Retrieved from http://journals1.scholarsportal.info/tmp/14962184124906306780.pdf

Ellis, R. (2003). Task-based language learning and teaching. Oxford, UK: Oxford University Press.

Ellis, R. (2008). The study of second language acquisition (2nd ed.). Oxford, UK: Oxford University Press.

Ellis, R., Loewen, S., Elder, C., Erlam, R., Philp, J., \& Reinders, H. (2009). Implicit and explicit knowledge in second language learning, testing and teaching. Buffalo, N.Y: Multilingual Matters.

Fareh, S. (2010). Challenges of teaching English in Arab world: Why can't EFL programs deliver as expected? Procedia-Social and Behavioral Sciences, 2(2), 3600-3604. Retrieved from http://www.sciencedirect.com/science/article/pii/S1877042810005999

Fotos, S., \& Ellis, R. (1991). Communicating about grammar: A task-based approach. TESOL quarterly, 25(4), 605-628. Retrieved from http://search.proquest.com/docview/85497180?accountid=9744

Fuente, M. J. D. L. (2002). Negotiation and oral acquisition of L2 vocabulary: The roles of input and output in the receptive and productive acquisition of words. Studies in Second Language Acquisition, 24(1), 81-112. Retrieved from http://search.proquest.com/docview/85552542? accountid=9744

Harmer, J. (2007). The practice of English language teaching. Essex, UK: Pearson Longman.

Herron, C., \& Tomasello, M. (1992). Acquiring grammatical structures by guided induction. The French Review, 65(5), 708-718. Retrieved from http://search.proquest.com/docview/58252036?accountid=9744

Khan, I. A. (2011). Learning difficulties in English: Diagnosis and pedagogy in Saudi Arabia. International Research Journal, 2(7), 1248-1257. Retrieved from http://interesjournals.org/ER/pdf/2011/July/Khan.pdf

Kumaravadivelu, B. (1992). Macrostrategies for the second/foreign language teacher. The Modern Language Journal, 76(1), 41-49. Retrieved from http://search.proquest.com/docview/58244229?accountid=9744

Kumaravadivelu, B. (1994). The postmethod condition: Emerging strategies for second/ foreign language teaching. TESOL Quarterly, 28(1), 27-48. Retrieved from $\mathrm{http} / / /$ search.proquest.com/docview/85577048?accountid=9744

Kumaravadivelu, B. (2003). Beyond methods: Macrostrategies for language teaching. Hartford, CT: Yale University Press.

Kumaravadivelu, B. (2006). Understanding language teaching: From method to postmethod. Mahwah, NJ: Lawrence Erlbaum Associates.

Kumaravadivelu, B. (2012). Language teacher education for a global society: A modular model for knowing, analyzing, recognizing, doing, and seeing. New York, NY: Routledge.

Li, D. (1998). "It's always more difficult than you plan and imagine": Teachers' perceived difficulties in introducing the communicative approach in South Korea. TESOL Quarterly, 32(4), 677-703. Retrieved from $\mathrm{http} / / /$ search.proquest.com/docview/85681390?accountid=9744

Liton, H. A. (2012). Developing EFL teaching and learning practices in Saudi colleges: A review. International Journal of Instruction, 5(2), 129-151. Retrieved from http://www.e-iji.net/dosyalar/iji_2012_2_8.pdf

Long, M. H. (1996). The role of the linguistic environment in second language acquisition. In W. C. Ritchie, \& T. K. Bhatia (Eds.), Handbook of second language acquisition (pp. 413-468). San Diego, CA: Academic Press.

Oxford, R. (2001). Integrated skills in the ESL/EFL classroom. ERIC digest ERIC Clearinghouse on Languages and Linguistics. Retrieved from http://search.proquest.com/docview/62284310?accountid=9744

Qashoa, H. S. (2013). Effects of teacher question types and syntactic structure on EFL classroom interaction. The International Journal of Social Sciences, 7(1), 52-62. Retrieved from http://www.tijoss.com/7th\%20volume/sulaiman.pdf

Rezvani, E. (2011). The effect of output requirement on the acquisition of grammatical collocations by Iranian EFL learners. Journal of Language Teaching and Research, 2(3), 674-674. Retrieved from $\mathrm{http}: / /$ search.proquest.com/docview/878347945?accountid=9744

Richards, J. C., \& Schmidt, R. (2010). Longman dictionary of language teaching and applied linguistics. Harlow, UK: Longman.

Risager, K. (2007). Language and culture pedagogy: From a national to a transnational paradigm. Buffalo, NY. 
Multilingual Matters.

Rogers, E. (2003). Diffusion of innovations (5th ed.). New York, NY: Free Press.

Selinker, L., \& Tomlin, R. (1986). An empirical look at the integration and separation of skills in ELT. ELT Journal, 40(3), 227-235.

Spradley, J. P. (1979). The ethnographic interview. New York, NY: Holt, Rinehart and Winston.

Stern, H. H. (1992). Issues and options in language teaching. Oxford, UK: Oxford University Press.

Su, Y. (2007). Students' changing views and the integrated-skills approach in Taiwan's EFL college classes. Asia $\begin{array}{lllll}\text { Pacific Education } & \text { Review, } & 8(1), & 27-40 . & \text { Retrieved from }\end{array}$ http://search.proquest.com/docview/62031956?accountid=9744

Su, Y. (2008). Promoting cross-cultural awareness and understanding: Incorporating ethnographic interviews in college EFL classes in Taiwan. Educational Studies, 34(4), 377-398. Retrieved from http://search.proquest.com/docview/61981698?accountid=9744

Sywelem, M., Al-Harbi, Q., \& Fathema, N. (2012). Learning style preferences of student teachers: A cross-cultural perspective. Institute for Learning style Journal, 1, 10-23. Retrieved from http://www.auburn.edu/academic/education/ilsrj/PreviousIssues/PDFs/Spring2012.pdf

Thornbury, S. (2012). How to teach grammar. Harlow, UK: Pearson Education.

Vanichakorn, N. (2009). Re-examine the use of the student's first language in the English as a foreign language classrooms: A cross-case analysis from undergraduate engineering students in Bangkok, Thailand. Journal of College Teaching \& Learning, 6(5), 1-16. Retrieved from http://search.proquest.com/docview/757173364?accountid=9744

Vogel, S., Herron, C., Cole, S. P., \& York, H. (2011). Effectiveness of a guided inductive versus a deductive approach on the learning of grammar in the intermediate-level college French classroom. Foreign Language Annals, 44(2), 353-380. Retrieved from http://search.proquest.com/docview/1010699652?accountid=9744

Widdowson, H. G. (1978). Teaching language as communication. Oxford, UK: Oxford University Press.

\section{Note}

Note 1. Kumaravadivelu (2012) also offers another rather different model, focusing on teachers' professional knowledge and education, that it is not directly relevant to the present discussion.

\section{Copyrights}

Copyright for this article is retained by the author(s), with first publication rights granted to the journal.

This is an open-access article distributed under the terms and conditions of the Creative Commons Attribution license (http://creativecommons.org/licenses/by/3.0/). 